\title{
Leading a team as new faculty
}

\author{
David L. Joyce, MD
}

\author{
From the Department of Cardiovascular Surgery, Mayo Clinic, Rochester, Minn. \\ Disclosers: Author has nothing to disclose with regard to commercial support. \\ Received for publication July 16, 2015; revisions received Sept 4, 2015; accepted for publication Sept 7, 2015; \\ available ahead of print Oct 12, 2015. \\ Address for reprints: David L. Joyce, MD, Department of Cardiovascular Surgery, Mayo Clinic, 200 First St SW, \\ Rochester, MN 55905 (E-mail: joyce.david1@mayo.edu). \\ J Thorac Cardiovasc Surg 2015;150:1410-2 \\ $0022-5223 / \$ 36.00$ \\ Copyright (c) 2015 by The American Association for Thoracic Surgery \\ http://dx.doi.org/10.1016/j.jtcvs.2015.09.056
}

From the moment you pick up a stethoscope for the first time to the placement of the final stitch on your last operative case before retirement, there is no more critical period in your career as a cardiothoracic surgeon than the first year after completing residency and fellowship training. It is during this time period that, as a new faculty member, you will demonstrate whether or not you possess the three A's (affability, ability, and availability) that are crucial for survival in the competitive world that is cardiothoracic surgery. At the end of that first year, there will be plenty of metrics available to judge your performance: mortality, operating room time, case volume, patient satisfaction scores, and cost per procedure (to name a few). But what will inevitably be lost behind each of these statistics is a truth about our profession that is fundamental to achieving success-cardiothoracic surgery is a team sport. There are 3 distinct teams that a new faculty member in cardiothoracic surgery must be prepared to lead on beginning a new job: the operating room team, the patient care team, and the administrative team.

\section{THE OPERATING ROOM TEAM}

The operating room team consists of the surgeon, the first assistant, the scrub technician, the circulating nurse, the anesthesia team, and (in the case of cardiac surgery) the perfusion team. In an ideal world, the new faculty member would be given the opportunity to handpick this team from a group of seasoned professionals with a high degree of consistency from day to day in terms of working with the same people. In reality, a good day for a new faculty member is one in which the unfamiliar faces in the operating room are individuals who have had some general background in scrubbing in on the type of procedure. Fortunately, there are ways to play your cards even when you've been dealt a difficult hand that will enable you to succeed in this arena. Every operating room will have an administrative manager who is ultimately responsible for making case assignments. One of the best investments you can make is to sit down with this person before your start date and go over the list of personnel who may be assigned to your room on any given day. The intent should be to learn the names,

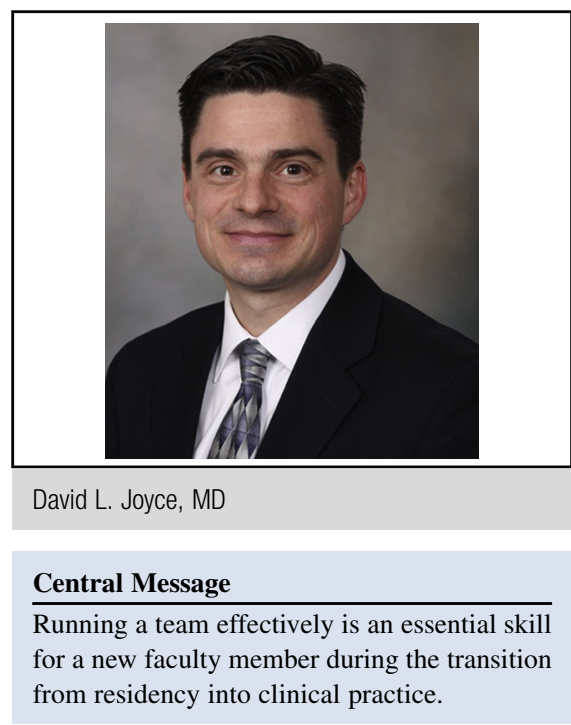

See Editorial Commentary page 1413.

background, and capabilities of everyone in the group before conducting the first preoperative briefing. This will serve to enhance the communication among team members, which is the foundation of successful team dynamics. Consider e-mailing a detailed plan of attack for each operation the night before to each member of the team. This will accomplish 3 things: (1) your team will greatly appreciate your clear communication and will be better prepared for the next day's case; (2) any new surgeon is likely to benefit from a thoughtful review of each of the details that one may encounter during a given operation; and (3) this will require you to identify who will be staffing your cases in advance, which when done routinely is very likely to result in more consistent team assignments by your operating room manager. A face-to-face meeting the night before an operation with any trainees who are expected to be participating in the surgery provides an excellent forum for reviewing the details of the case and addressing any teaching points in an unstressful environment. Above all, never underestimate the capacity for good leadership to transform even the most dysfunctional surgical team into an elite platoon in the operating room.

Of course, despite the best laid plans you may find yourself in the middle of a bad situation in which the case demands a higher level of expertise than you have been given on that particular day. In these situations, there are 3 steps you can take to mitigate any adverse outcomes. First, you must identify the potential for danger early, before 
things unravel and a disaster occurs. Second, slow down. As anyone who trained under surgical master R. Scott Mitchell can tell you, surgery is like playing chess. The worst thing you can do after making a mistake is to rush the next move. It is precisely at that moment that you must stop and calculate what the best next step should be. Third, do not hesitate to request the presence of more experienced individuals if things aren't going well. This applies to anesthesia, surgical assistants, scrub techs, and anyone else you need to help you complete the case safely. Obviously in this situation there is some risk that you will strike a blow to the ego of the people whose help you need the most. For this reason, it is generally best to seek first the assistance of a more experienced surgeon, even if it's just to help you manage the stress of not having the " $\mathrm{A}$ " team by your side.

\section{THE PATIENT CARE TEAM}

Between the time your patient presents for their first clinic appointment and the last outpatient follow-up, there are 3 primary groups of providers that will have a major influence on whether the patient achieves a successful outcome: physicians, advanced practice providers, and nurses. The physicians typically engaged in the preoperative and postoperative care include intensivists, cardiologists, pulmonologists, oncologists, and consultants from other specialties. Most residency training programs will also assign 1 or more residents to an individual surgeon's service. Perhaps the greatest challenge in interfacing with these members of your team involves the competing interests with respect to critically ill patients who have had complications. Implementing collaborative leadership techniques in these difficult situations will serve to align the postoperative care team's priorities toward the ultimate survival and recovery of the patient. Most of the patients who are likely to struggle in the postoperative period can be identified on the basis of their comorbidities and preoperative risk factors. When consulting on the case of a patient who has the potential for a challenging postoperative course, consider asking an intensivist leader to consult on the patient before surgery and weigh in on whether he or she feels that the patient has an acceptable risk. If a multidisciplinary conference exists to review these kinds of cases with the cardiology team or tumor board, this is another ideal mechanism for establishing buy-in from the rest of your team, so when challenges do occur, you don't have to engage in philosophic discussions about whether the patient should have ever been operated on in the first place.

The advanced practice providers include the physician assistants and nurse practitioners who are tasked with the day-to-day management of your surgical service, as well as with handling issues that arise in the outpatient setting. Whereas the residents' role in the postoperative care process may be limited because of their limited tenure on your service, the physician assistants and nurse practitioners will have the benefit of an extended period to learn your style of caring for patients. It is worth noting that there is a perception among some nurse practitioner and physician assistant groups that the term "midlevel provider" implies a lack of knowledge with regard to patient care. Regardless of the semantics used, the successful junior faculty member is one who recognizes the value of having an assistant who can function as your clone when it comes to dealing with patients, referring physicians, and other members of the patient care team. No matter how light your caseload and other responsibilities, there will not be enough of you to go around for all the responsibilities that will be placed on you. The best timemanagement strategies in the world cannot compete with having someone who can intervene on your behalf to improve postoperative decision making, patient satisfaction, and customer service to the referring doctors. The key to achieving this kind of relationship is first to understand the strengths and limitations of your advanced practice provider. Once you have established a level of trust, maintaining open lines of communication in both directions is a critical strategy for avoiding complications. Part of this communication should include asking the opinions of your advanced practice providers in clinical decision making. No matter how meticulous your involvement in a patient's care may be, it is likely that your advanced practice provider will bring ideas to the discussion that you had not considered and will enhance the outcome of your patients. This obviously requires a certain degree of humility, but when one considers the vast experience that many of these providers bring to the table, it shouldn't result in irreversible damage to a surgeon's ego to acknowledge the value they can add. Another key to maximizing the value of your "physician extenders" is to maintain a relatively consistent set of treatment preferences (which are based on medical evidence when that is available). Ultimately, as your emissary to the rest of the hospital, it will be easier for them to represent you effectively if you have discussed with them your thought processes on managing patients and invited a dialog that allows them to understand the situations when you deviate from the playbook.

Depending on your practice environment, you may also have the opportunity to work closely with nursing in the management of your patients. As with the advanced practice providers, these members of your team often come with a wealth of experience. In addition, they also have the advantage of being on the front lines in terms of observing patient trends and acting on the minute-tominute variability that can occur in the postoperative setting. During rounds, try to make a routine practice of asking the nurse what concerns or insights they might 
have on your patients' progress. There will often be important information that is not contained in the electronic medical record, and as with the other members of the team, they may have ideas and perspectives on a management strategy that will ultimately benefit you and your patient.

\section{THE ADMINISTRATIVE TEAM}

Of all the professionals who interact with you on a routine basis, your administrative assistant is likely to be the individual who has the greatest impact on your quality of life, because they control access to your most valuable asset: time. Many new faculty members do not appreciate the degree to which their administrative assistant can serve as their most important public relations asset when communicating with patients and referring providers. For someone who is trying to build up their case volume early on, this can be a vital part of establishing a reputation within an institution. The better your administrative assistant understands your preferences and priorities, the more effective that person will be in helping you accomplish your goals.

In most academic positions, you will also interact with a team of research personnel who will be responsible for managing enrollment in clinical trials, database entry, and in some cases quality initiatives. Although these members of your team may not interface with you on a regular basis, it would be prudent to schedule recurring appointments to review your goals and current progress in each of these areas. From the standpoint of your Society of Thoracic Surgeons (or equivalent) database, a monthly review of your outcomes will both ensure that you are keeping up with data entry and identify any trends that may require your attention when it comes to optimizing your outcomes in the quarterly and yearly reports. Many academic surgeons will have a much more extensive research team if they are given protected time to spend integrating into a laboratory. This first year represents an important crossroads in developing the expectations and relationships with this important group that will ultimately build the foundation for future academic endeavors.

Although coding and billing represent skills that few, if any, residency programs dedicate attention to, these processes represent a critical component of your practice in terms of how your program's performance is viewed at higher levels within the institution. Maintaining an open dialog with your coders will enhance their ability to capture more revenue by accurately billing for visits and procedures. If time permits, a regular review of your relative value units is a worthwhile habit to form early in your career as a mechanism of tracking your productivity and a strategy to accurately characterize your surgical volume for billing purposes. An accurate accounting of your relative value unit production will also enhance your ability to capture outcomes and complications for quality assurance and quality initiative purposes.

\section{CONCLUSIONS}

Finally, any discussion of teamwork in the arena of cardiothoracic surgery would be incomplete without at least mentioning the importance of mentorship. Just as every team captain needs a good coach, every young surgeon needs someone who can serve as an advisor on difficult cases, complications, and the numerous other challenges that arise during the first year. It is primarily through working with mentors that you will observe and learn to emulate the character traits that are necessary to build a productive team. You may very well encounter challenging personalities among your team members, difficulties earning the respect of team members who are older and have more clinical experience than you, and other interpersonal obstacles in building your team. Although a number of books and leadership training courses are available that provide great resources for managing these types of situations, it is doubtful that any of these are as effective as seeking the advice from a mentor who has travelled down the same road before you.

In summary, the team you will lead on your first day as a new faculty member will include a diverse range of professionals including your operating room team, your patient care team, and your administrative team. Although the roles they play in helping you achieve your professional goals will be highly varied, developing a close relationship with each of these members of your team will enhance your communication and productivity as you work together as a unit. You will find that your teammates can serve as force multipliers as you strive to achieve the time-management skills necessary to meet the increasing demands of clinical, research, and administrative responsibilities. By approaching your position with a degree of humility, you will acknowledge that you are comfortable not always having all the answers, but rather understand that (in the words of William Mayo), "No one is big enough to be independent of others." As chief adviser for US Army surgical services during World War I and chair of the committee that would become the General Medical Board of the Council for National Defense, Mayo understood from his military experience the advantages of coordinating a team in which members are empowered to function independently and synergistically to achieve a common goal. Collaborative leadership of this variety can be your best weapon in avoiding complications in and out of the operating room. In time, these skills will prepare you to take on leadership roles within your hospital, professional organizations, and peer groups, or even at a national level. 